\title{
Nanocomposite of Graphene Oxide Encapsulated in Polymethylmethacrylate (PMMA): Pre-Modification, Synthesis, and Latex Stability
}

\author{
Hui Wang ${ }^{1,2,+}$, Letian Wang ${ }^{2,+}$, Shanyu Meng ${ }^{2}$, Hanxue Lin ${ }^{1}$, Melanie Correll ${ }^{2}$ and \\ Zhaohui Tong $2, *(D)$ \\ 1 College of Material Science and Engineering, Central South University of Forestry and Technology, \\ Changsha 410004, China; huiwanguf@gmail.com (H.W.); linhanxue201@outlook.com (H.L.) \\ 2 Department of Agricultural and Biological Engineering, IFAS, University of Florida, Gainesville, \\ FL 32611-0570, USA; leoltwang@gmail.com (L.W.); shanyu@ufl.edu (S.M.); correllm@ufl.edu (M.C.) \\ * Correspondence: ztong@ufl.edu \\ + These authors contributed equally to this work.
}

Received: 25 July 2020; Accepted: 14 August 2020; Published: 17 August 2020

\begin{abstract}
The compatibility of graphene oxide with its dispersion medium (polymer) plays a critical role in the formation of nanocomposite materials with significant property improvements. Environmentally friendly miniemulsion polymerization, which allows a formation of nanoencapsulation in an aqueous phase and high molecular weight polymer/composite production is one promising method. In this study, we screened a series of amphiphilic modifiers and found that the quaternary ammonium (ar-vinyl benzyl) trimethyl ammonium chloride (VBTAC) pending carbon double bonds could effectively modify the graphene oxide (GO) to be compatible with the organophilic monomer. After that, free radical miniemulsion polymerization successfully synthesized stable latex of exfoliated poly (methyl methacrylate) (PMMA)/ GO nanocomposite. The final latex had an extended storage life and a relatively uniform particle size distribution. X-ray powder diffraction (XRD), transmission electron microscopy (TEM), and scanning electron microscopy (SEM) analysis of this latex and its films indicated successful encapsulation of exfoliated nano-dimensional graphene oxide inside a polymer matrix.
\end{abstract}

Keywords: Graphene oxide; Exfoliation; Nanocomposites; Encapsulation; Stable latex

\section{Introduction}

Nanocomposites consisting of polymer and inorganic particles with a sub-micron scale, such as carbon black, carbon nanotubes, graphene, and nanoclay, have been extensively studied in the last decades because these materials possess superior mechanical, thermal, electric, or gas barrier properties [1-4]. Among these inorganic materials, graphene and graphene oxide (GO) have attracted interest since they can prepare various functional nanocomposites for different applications in the energy and environmental areas [5-9]. Along with its high thermal (up to $5000 \mathrm{w} /(\mathrm{m} . \mathrm{k}$.)) and electrical conductivity (up to $6000 \mathrm{~S} / \mathrm{cm}$ ), graphene is also an excellent candidate as a superior enforcement nanomaterial because it has strong mechanical properties with Young's modulus of approximately $1 \mathrm{TPa}$, the strength of $130 \mathrm{GPa}$ [10-13] and high specific surface area when it is dispersed into the polymer matrix.

Graphite is a layered material consisting of stacked graphene sheets in parallel. It consists of six hexagonally arranged $\mathrm{sp}^{2}$ hybridized carbon atoms in a 2-D sheet-like morphology with one atom thickness [14]. However, natural graphene sheets lack accessible functional groups on their surface for the polymer to be intercalated or loaded, and this result in the incompatibility between polymer 
matrixes with the natural graphite sheet. However, graphite can be easily converted to graphene oxide (GO) through oxidation [15-17], which provides multiple oxygen-containing functional groups on its surfaces, such as hydroxyl, carboxyl, and epoxy groups. All these functional groups are crucial for the subsequent functionalization treatment, as well as the incorporation with polymers [18]. GO is in a layered structure and its oxidative functionalities are located in the basal plane of the graphene sheet causing hydrophilicity, which results in exfoliation to the nanoscale platelet and dispersion in the aqueous phase [19]. Putz et al. (2010) described the dispersion of graphene nanosheets using a flow-through ultrasonication method followed by a vacuum-assisted self-assembly (VASA) technique to prepare highly ordered, homogeneous polymer nanocomposites with the layered graphene oxide using both hydrophilic and hydrophobic polymers [20]. GO and hydrophilic polymers can form homogeneous nanocomposites but possess weak and volatile mechanical properties because they can absorb water very easily. Poor interaction between the hydrophilic GO and the hydrophobic polymer is a major concern for preparing high-quality GO-based nanocomposites. Therefore, GO has been modified by an amine, an alkyl lithium reagent, isocyanate, and di-isocyanate, amphiphilic polymers such as poly (sodium 4-styrene sulfonate), 7,7,8,8-tetracyanoquinodimethane, sulfonated polyaniline, and diazonium salt to be hydrophobic and amenable to different synthetic polymers. However, these methods including solution blending, bulk polymerization, and melt-intercalation [21-23] require the use of toxic organic solvents, high temperature, or produce the non-uniform distribution of the GO sheet in the polymer matrix.

It is known that nanocomposites in an aqueous form show many unique advantages over their bulk and solvent forms in terms of improved environmental impacts, energy-saving, and product control [3,24]. To increase the compatibility between a hydrophilic GO sheet and organophilic polymers, the oil-in-water system has been adapted to resolve this incompatibility issue as well as to avoid the use of environmentally harmful organic solvents. For example, Thomassin et al. (2014) found that GO served as the surfactant and adsorbed on the PMMA surface through the precipitation polymerization process in a water/methane mixture [25]. Wang et al. (2004) described a method to intercalate GO into a monomer solution followed by in-situ emulsion polymerization for the production of the poly (methyl methacrylate) (PMMA)/GO composite. The results showed that mechanical properties decreased with the increase of the ratio of GO because GO was not fully exfoliated into a nanometer scale [26]. Graphene-polystyrene (PS) nanocomposites with high electrical conductivity have been successfully synthesized via emulsion polymerization followed by a GO reduction reaction using hydrazine hydrate. The PS particles were linked with GO edges, which increased the organophilic property of GO [27]. GO or RGO (reduced graphene oxide) nanocomposites have been studied via various oil-in water systems including ultrasonic-assisted in-situ emulsion polymerization [28], microemulsion polymerization [29], in-situ seed emulsion polymerization [30], picking emulsion polymerization [31], reversible addition fragment chain transfer (RAFT) emulsion polymerization [32], and surfactant-free emulsion polymerization followed by electrostatic interaction methods [33]. These nanocomposites have high conductivity and can also serve as coating materials to encapsulate phase change materials. Improvements in the distribution of GO or RGO in the polymer matrix could lower the percolation threshold and provide greater electrical conductivities [33]. In these aforementioned colloidal latex systems, polymer particles are either attached on the edge of the GO sheet or coated by the GO sheets, which impedes the aggregation of the GO sheets. However, in these colloidal latex systems such as emulsion, precipitation, and macroemulsion, the GO sheets are randomly separated by the polymer particles instead of the formation of a highly ordered and fully exfoliated nanoscale dispersion in the polymer matrix. The incompatibility between the hydrophilic GO and the hydrophobic polymer still requires further improvement due to the weak intercalation of the polymer nanoparticles into the graphene-based planes.

Miniemulsion has the advantages over emulsion polymerization in the synthesis of stable nanocomposite latex. The loci of polymerization for the miniemulsion is the monomer droplets instead of micelles in emulsion which avoids mass transfer and enables the filler encapsulation by 
polymer droplets [34,35]. This method produces not only stable latex of nano-droplets with a diameter of 50-500 $\mathrm{nm}$ and narrow particle size distribution but also nanocomposites with high molecular weight because the bimolecular termination is suppressed [36]. Miniemulsion polymerization has been extensively studied to intercalate inorganic particles such as nanoclay, carbon black, carbon nanotubes, $\mathrm{TiO}_{2}$ into the polymer matrix $[3,4,37]$ to form a uniform and stable latex of nanocomposites with the improved mechanical, thermal and barrier properties. A few researchers have also synthesized the GO or graphene-based nanocomposites via miniemulsion polymerization. For example, nano-dimensional GO sheets were armored on the polystyrene nanoparticles via miniemulsion polymerization, but the reduction occurred during polymerization resulting in the loss of colloidal stability [38]. This method has also been applied to prepare hollow hybrid polymer/GO nanoparticles [31,38-40] and GO was coated on the surface but not encapsulated into polymer nanoparticles. A few researchers described for the synthesis of exfoliated GO/polymer nanocomposites prepared with pre-modified GO via miniemulsion polymerization using a reactive surfactant, 2-acrylamido-2-methyl-1-propanesulfonic acid (AMPS) [19], poly(ionic liquid) (PIL) [41], and r-methacryloxypropyl trimethoxy silane (MPS) [42]. The monomer type, the addition of conventional surfactant, $\mathrm{pH}$ value, and ionic strength, have proved to affect the polymerization kinetics, latex stability, nanocomposite properties, and the intercalation degree for both traditional miniemulsion polymerization or picking miniemulsion polymerization $[39,43,44]$. In miniemulsion polymerization, the modifiers have shown their effectiveness to prepare exfoliated polymer encapsulated GO nanocomposite latex. However, it is unclear how different modifiers could affect the compatibility between the GO and the organophilic monomer, the latex stability, the reaction kinetics, and the exfoliation and encapsulation degree.

In this study, GO was prepared from a low cost, bulk, raw graphite via a modified Hummers' method [45]. Then, we used different amphiphilic modifiers (Figure 1) to not only intercalate into the graphene platelet but also transfer GO from hydrophilic to organophilic. The modifiers included the reactive surfactant (ar-vinyl benzyl) trimethyl ammonium chloride (VBTAC), 2-acrylamido-2-methyl-1-propane sulphonic acid (AMPS), traditional surfactant sodium dodecylbenzene sulfonate (SDBS), cationic ammonium-based surfactants with different carbon chains (octadecyl trimethylammonium bromide OTAB, trimethyl(tetradecyl) ammonium bromide (MTAB), and an amphiphilic modifier derived with highly crosslinked polymer lignin (quaternary ammonium lignin, QAL) [4,46]. GO was modified with these modifiers and then dispersed in the oil/water system. The stability and distribution of the modified GO on the oil/water system determined the optimized GO modifier for further miniemulsion polymerization. After that, we conducted miniemulsion polymerization to synthesize stable latex with a PMMA encapsulated the nano-dimensional and exfoliated GO sheet. The uniform distribution of exfoliated GO in this system is expected to achieve significant property improvement and stable latex will benefit for long-term storage.
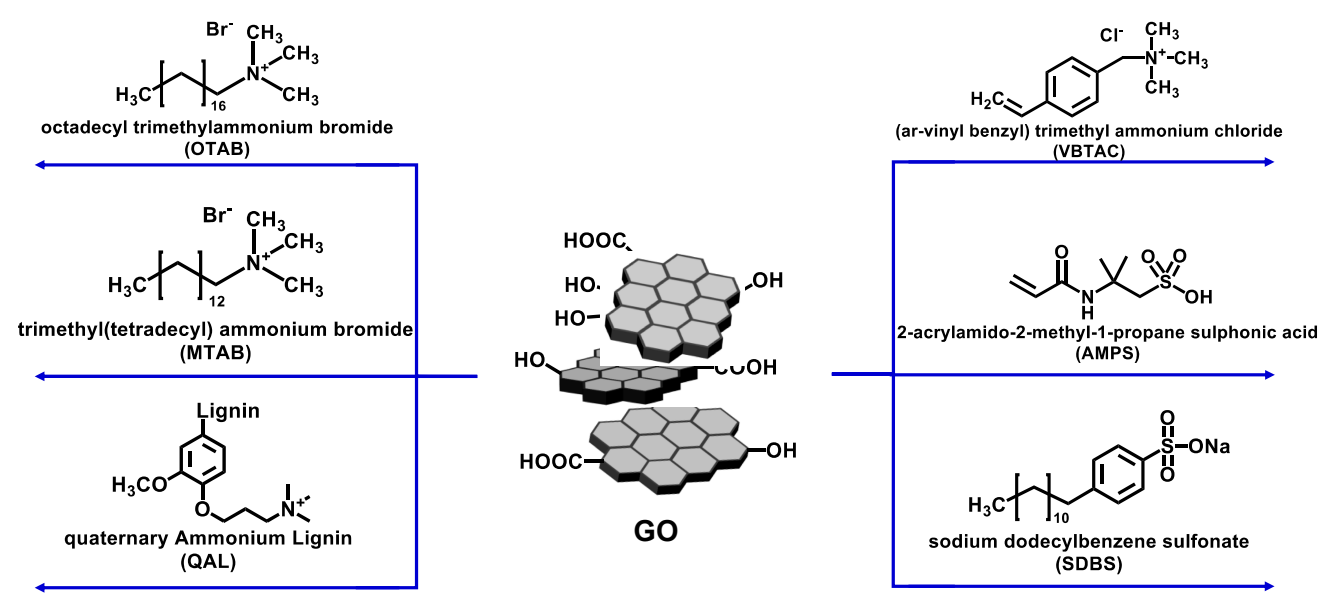

Figure 1. The chemical structures of graphene oxide (GO) and different modifiers. 


\section{Materials and Methods}

\subsection{Materials}

The lignin was extracted from the fermentation broth of a bioethanol process, which involves liquefaction plus a simultaneous saccharification and fermentation process $(\mathrm{L}+\mathrm{SScF})$ using sugarcane bagasse as a raw material [47]. Raw graphite flakes with an average size of $20 \mu \mathrm{m}$ were purchased from Sigma-Aldrich Inc. (St. Louis, MO, USA) and used as received. Monomer methyl methacrylate (MMA), $99 \%$, was purchased from Sigma-Aldrich Inc., and the inhibitor (monomethyl ether hydroquinone) was removed by passing through a glass column filled with aluminum oxide powder. (Vinyl benzyl) trimethyl ammonium chloride (VBTAC, 99\%), 2-acrylamido-2-methyl-1-propane sulphonic acid (AMPS), sodium dodecylbenzene sulfonate (SDBS, technical grade), Triton 405 (TX-405, 70\% solution in water,), hexadecane (HD, 99\%), 2,2'-Azoisobutyronitrile (AIBN, 98\%), and 4-methoxyphenol (99\%), were all purchased from Sigma-Aldrich Inc. and used as received. Polyvinyl alcohol (PVA, 99\%, $\mathrm{Mw}=86,000)$ granules, trimethylamine (TMA, $50 \%$ aqueous solution), and epichlorohydrin (ECH, 99\%) were purchased from Thermo Fisher Scientific (Waltham, MA, USA). Sulfuric acid (98\%), potassium permanganate (99\%) and hydrogen peroxide (30\%) were purchased from Fisher Scientific and used as received. Silver nitrate $(0.025 \mathrm{M})$, was purchased from Ricca Chemicals (Arlington, TX, USA). Quaternary ammonium lignin (QAL) was synthesized according to our previous study [48].

\subsection{Experiments}

\subsubsection{Preparation of Graphene Oxide (GO)}

GO was prepared according to the modified Hummers method [46]. In an ice bath, powdered flake graphite $(10 \mathrm{~g})$ and sodium nitrate $(5 \mathrm{~g})$ were added to $98 \%$ sulfuric acid $(230 \mathrm{~mL})$ in a $1.5 \mathrm{~L}$ flask that was previously cooled to $-5^{\circ} \mathrm{C}$ in a freezer. Potassium permanganate $(30 \mathrm{~g})$ was slowly added in a stirred suspension while the mixture temperature carefully remained below $20^{\circ} \mathrm{C}$. The ice bath was then removed, and the mixture was heated to $35^{\circ} \mathrm{C}$ and kept at that temperature for $30 \mathrm{~min}$. Deionized water $(460 \mathrm{~mL})$ was then slowly added to the mixture, causing an increase in temperature to about $100{ }^{\circ} \mathrm{C}$. The diluted mixture was maintained at $100^{\circ} \mathrm{C}$ for $15 \mathrm{~min}$ before it was further diluted with warm deionized water $(420 \mathrm{~mL})$ and hydrogen peroxide $(3 \%, 100 \mathrm{~mL})$. The yellow-brownish GO was separated by a vacuum filtration process then washed repeatedly with deionized water until the effluent became neutral. GO was then re-dispersed in water and freeze-dried in a Triad freeze dryer (Triad ${ }^{\mathrm{TM}}$ Labconco, Millrock Technology, Inc., Kingston, NY, USA) to preserve its original structure and property for further use.

\subsubsection{Pre-Modification of GO}

To further exfoliate the GO, the GO (before any further treatments) was dispersed in deionized water to form a suspension at a concentration of $1 \mathrm{wt} . \%$. Ultrasonication was applied to the suspension in an ultrasonic homogenizer with the energy equivalent of $1.35 \mathrm{kWh}$, the power of $300 \mathrm{~V}$, and at a power setting of $90 \%$ and a pulse setting of $90 \%$ (BioLogics, Inc., Cary, NC, USA) in an ice bath. After sonication, a certain amount of the modifiers including VBTAC, MPS, SDBS, OTAB, MTAB, and QAL were added to the GO suspension and the concentration of each modifier was kept at $20 \mathrm{wt} . \%$ based on the GO weight. The suspension was stirred for $24 \mathrm{hrs}$ to allow the modification reaction between each modifier and GO. The modified GO suspensions were observed at room temperature $\left(23^{\circ} \mathrm{C}\right)$ to determine their solubility in water. Several modified GO suspensions were further dispersed into the monomer or monomer/water mixture to determine their stability in each solvent. For example, the VBTAC treated GO suspension was dialyzed in deionized water using a $3.5 \mathrm{kD}$ dialysis tube (Spectrum Laboratories, Inc., Rancho Dominguez, CA, USA) until no chlorine could be detected by silver nitrate (about $3-4$ days). After that, the modified GO samples were freeze-dried (Triad ${ }^{\mathrm{TM}}$ Labconco) to preserve their original structure and property. 
2.2.3. Miniemulsion Polymerization of Methyl Methacrylate (MMA) in the Presence of Graphene Oxide (GO)

In a typical run as shown in the recipe in Table 1 , the oil phase composed of $0.5 \mathrm{~g}$ of co-stabilizer hexadecane, $0.1 \mathrm{~g}$ of AIBN, $6 \mathrm{~g}$ of monomer MMA, and varying quantities of GO was mixed and then magnetically stirred for $30 \mathrm{~min}$. The mixture was ultrasonicated in an ice bath for $3 \mathrm{~min}$ using an ultrasonic homogenizer (300V, BioLogics, Inc.) at an energy equivalent of $0.27 \mathrm{kWh}$ and on a $90 \%$ power and $90 \%$ pulse setting. The water phase mixture composed of $0.17 \mathrm{~g}$ of TX-405, various amounts of PVA, was magnetically stirred in an ice bath for $30 \mathrm{~min}$. PVA was used as a co-stabilizer to improve latex stability. The monomer phase was then transferred to the water phase, the mixture was then ultrasonicated again using the ultrasonic homogenizer with the energy equivalent of 0.08 $\mathrm{kWh}$ and on a $90 \%$ power and $90 \%$ pulse setting. The obtained miniemulsion was transferred into a three-neck flask equipped with a condenser, a mechanical overhead stirrer, and a temperature control unit. The miniemulsion was stirred for another $30 \mathrm{~min}$ at room temperature and degassed with nitrogen. The polymerization was then initiated by increasing the temperature to $70 \pm 2{ }^{\circ} \mathrm{C}$ and the reaction was allowed to taken place for $8 \mathrm{hrs}$. under continuous mechanical stirring. Upon $8 \mathrm{hrs}$. reaction, several drops of $2 \% 4$-methoxy phenol were added to terminate the polymerization.

Table 1. The basic recipe for the synthesis of PMMA/GO nanocomposite latex via miniemulsion polymerization.

\begin{tabular}{ccccc}
\hline Mixtures & Component & $\begin{array}{c}\text { Amount } \\
\text { Added (g) }\end{array}$ & $\begin{array}{c}\text { Percentage/Total } \\
\text { (wt.\%) }\end{array}$ & $\begin{array}{c}\text { Percentage/Monomer } \\
\text { (wt. } \%)\end{array}$ \\
\hline \multirow{3}{*}{ Oil Phase } & Methyl Methacrylate & 6 & $20.00 \%$ & $100.00 \%$ \\
& Hexadecane & 0.5 & $1.67 \%$ & $8.33 \%$ \\
& AIBN & 0.1 & $0.33 \%$ & $1.67 \%$ \\
\hline \multirow{2}{*}{ Water Phase } & Poly Vinyl Alcohol (10\% solution) & 0.6 & $2.00 \%$ & $10.00 \%$ \\
& Triton-405 & 0.17 & $0.57 \%$ & $2.83 \%$ \\
& Deionized Water & 24 & $80.00 \%$ & $400.00 \%$ \\
\hline
\end{tabular}

\subsection{Characterization}

Fourier transform infrared spectrometry (FTIR) spectra were recorded on a Thermo Nicolet Magna 760 FTIR spectrometer (Thermo Scientific). Each sample $(0.1-2 \mathrm{mg}$ ) was mixed with $160 \mathrm{mg}$ potassium bromide to prepare a pellet form ready for the FTIR measurement. Each sample was taken for 32 scans and in the scanning range from 400 to $4000 \mathrm{~cm}^{-1}$ and at a resolution of 4 .

X-Ray Diffraction (XRD) measurements were performed on a Phillips XPert MRD instrument (PANalytical, Almelo, The Netherlands) with Cu K radiation source $(\lambda=1.54056 \AA)$ and at a voltage of $45 \mathrm{~V}$, step size of $0.016^{\circ}$, scan step time of $5 \mathrm{~s}$, scan angle from $5^{\circ}$ to $60^{\circ}$. The $\mathrm{d}(001)$ basal spacing of the raw graphite, GO, and the polymerized composite was calculated using the Bragg equation: $\mathrm{d}=\lambda / 2 \sin \theta$. Where $\mathrm{d}$ is the interlayer distance, $\lambda$ is the wavelength of the $\mathrm{X}$-Ray source (Cu K-alpha, $\lambda=0.15418 \mathrm{~nm}), \theta$ is the diffraction angle.

The molecular weight $(\mathrm{Mw})$ of the PMMA and its nanocomposites with GO together was measured by a size exclusion chromatography (SEC) via an Agilent Technologies 1260 (Santa Clara, CA, USA) series HPLC system equipped with a refractive index detector (RID) and a multiple wavelength detector (MWD). Three columns (Agilent Technologies) were connected in series, including a PLgel-mixed B, a PLgel-mixed E ( $5 \mu \mathrm{m}$ with a pore size of $10,000 \AA)$, and a PLgel-mixed E ( $5 \mu \mathrm{m}$ with a pore size of $100 \AA$ ). . All samples were dissolved in HPLC-grade tetrahydrofuran at a concentration of $0.2 \mathrm{wt} . \%$. After that, the solution was filtered through a $0.22 \mu \mathrm{m}$ syringe filter. In each run, $50 \mu \mathrm{L}$ filtered solution was injected, the thermostat temperature and flow rate were set at $25^{\circ} \mathrm{C}$ and $1 \mathrm{~mL} / \mathrm{min}$, respectively. All results were processed using ChemStation software with the GPC analysis (Rev.B.04.03, Agilent Technologies). Molecular weight was calculated based on a universal calibration using a set of polystyrene standards. 
Thermogravimetric analysis (TGA) was performed using a Mettler Toledo (Columbus, OH, USA) thermal analyzer. For each sample, 3-10 mg sample was heated at a heating rate of $10^{\circ} \mathrm{C} / \mathrm{min}$ from $30^{\circ} \mathrm{C}$ to $1000^{\circ} \mathrm{C}$ and in a constant nitrogen flow of $100 \mathrm{~mL} / \mathrm{min}$.

Dynamic light scattering (DLS) was used to estimate the size and size distribution of the GO samples and the miniemulsions after polymerization. A zeta sizer ZS3600 with noninvasive backscatter under $500 \mathrm{MW}$ and $532 \mathrm{~nm}$ laser (Malvern Panalytical, Westborough, MA, USA) was used. All samples at a concentration of 0.05 or $0.1 \%$ were transferred to the standard $3.5 \mathrm{~mL}$ square cuvettes for the analysis.

Scanning electron microscopy (SEM) and transmission electron microscopy (TEM) were used to study the morphologies of graphite, GO, polymerized particles in miniemulsion, and the melting latex films. SEM was carried out on an FEI XL 40 FEG SEM (FEI company, Hillsboro, OR, USA) at an operation voltage of $10 \mathrm{keV}$. Miniemulsion sample was dried on a conductive carbon tab then coated with a gold-palladium coating $(\mathrm{Au} / \mathrm{Pd}$ ). TEM was conducted on a JEOL 200CX TEM (JEOL instruments, Peabody, MD, USA) with a $100 \mathrm{keV}$ accelerating voltage. Miniemulsion samples were dried on carbon type A grids and air-dried before analysis. Melt film samples were prepared as follows. Miniemulsions were dropped in the carbon grids and air-dried. After that, the grids with samples were put in the oven at a set of temperature $160^{\circ} \mathrm{C}$ ( $>$ PMMA melting temperature) and kept for $6 \mathrm{hrs}$. Then, the grids with the melting polymer films were used for both SEM and TEM measurements.

\section{Results}

\subsection{Modification of GO Using Different Modifiers}

To facilitate the encapsulation and exfoliation of GO into polymer droplets, GO must be well dispersed into the monomer phase before miniemulsion polymerization. Figure 2 shows the stability of the neat GO and the modified GO treated by different modifiers in water. It was observed that GO modified with AMPS (c) and SDBS (d) behaved quite similarly as the neat GO (a), which had good dispersibility in water. The oxidation reaction to convert graphene to $\mathrm{GO}$, as expected, introduced functional groups such as $\mathrm{COOH}$ and $\mathrm{OH}$ on its surface; therefore, $\mathrm{GO}$ had good water dispersibility. However, the GO treated with VBTAC (b), OTAB (e), and MTAB (f) precipitated out of the solution, which indicated that water-soluble functional groups on the GO surface were occupied by these modifiers and the modified GO were converted from hydrophilic to organophilic. This was likely caused by the fact that cationic quaternary ammonium end groups of VBTAC, OTAB, and MTAB modifiers were bonded to the negative functional groups on the GO sheet. We also observed that OTAB (C18) and MTAB (C14) could significantly increase the viscosity of GO/monomer mixture, which impeded the oil phase to disperse into the aqueous phase in the following miniemulsion step and possibly reduced the polymerization rate [3]. Only VBTAC with a short phenolic structure had an acceptable viscosity for further dispersion into stable miniemulsion.

We further introduced another cationic quaternary ammonium modifier (QAL) that was prepared from our lab. QAL was produced by reacting lignin with epoxypropyl trimethylammonium chloride (ETAC) and carried a crosslinking phenolic backbone structure and cationic quaternary ammonium end groups. SDBS was used as a comparison because it was an anionic surfactant that was reported to provide electrostatic stabilization for GO $[48,49]$. Figure 3 shows the dispersion of the modified GO in the monomer/ water mixture using VBTAC, SDBS, and QAL. Since MMA had a lower density $\left(0.94 \mathrm{~g} / \mathrm{cm}^{3}\right)$ than water, it stayed afloat on the aqueous phase. It was clearly shown that only VBTAC modified GO stayed on the monomer MMA phase, the SDBS modified GO occupied in both water and monomer phases. Surprisingly, the QAL modified GO remained in the water phase. The network phenolic backbone structure of QAL might inhibit the contact between the cationic quaternary ammonium groups and the GO functional groups. Therefore, VBTAC was chosen as the modifier because it not only converted GO from hydrophilic to organophilic but also owned the reactive acrylic groups, which allowed further combination with the monomer MMA together during miniemulsion polymerization. 


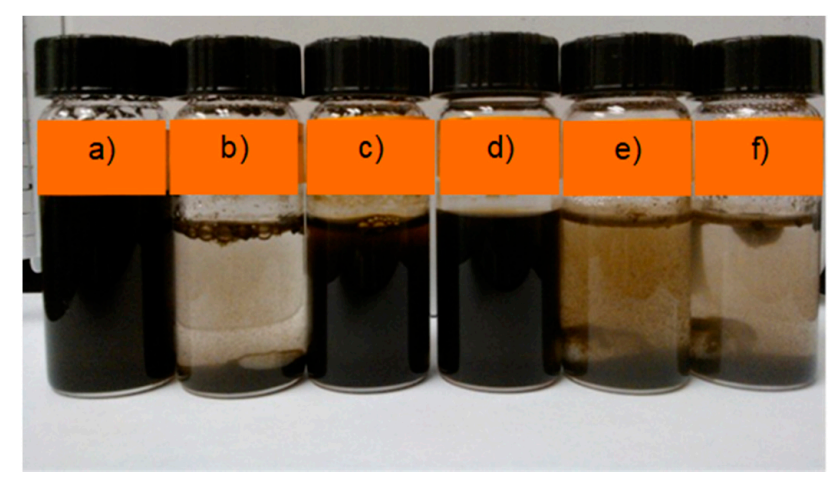

Figure 2. The visual appearance of $0.02 \mathrm{~g} \mathrm{GO}$ and GO treated with $0.01 \mathrm{~g}$ different modifiers in the deionized water, 10 minutes after agitation was stopped, (a) neat GO, (b) GO with VBTAC, (c) GO with AMPS, (d) GO with SDBS, (e) GO with OTAB, (f) GO with MTAB.

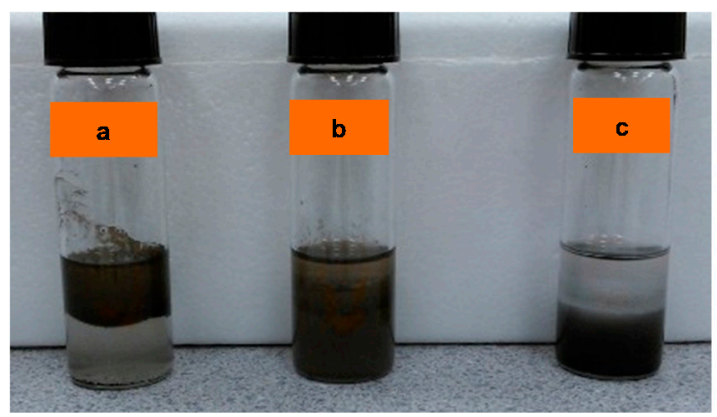

Figure 3. The visual appearance of $0.02 \mathrm{~g}$ GO with different modifiers in the MMA/water (50/50 v/v) mixture, 10-minute sitting after sonication, (a) VBTAC, (b) SDBS, (c) QAL.

\subsection{Fourier Transform Infrared Spectrometry (FTIR)}

FTIR was used to confirm the chemical shift of the graphite, GO, reduced GO, and VBTAC-modified GO. As shown in Figure 4, GO had the represented peaks including the stretching vibration of carboxyl groups $(-\mathrm{COOH})$ around $1700 \mathrm{~cm}^{-1}$ (a), the vibration of in-plane tertiary hydroxyl groups $(-\mathrm{OH})$ at $1400 \mathrm{~cm}^{-1}(\mathrm{~b})$ and the vibration of alkoxy (C-O) around $1050 \mathrm{~cm}^{-1}(\mathrm{c})$ in comparison with the graphene. It indicated that the original graphite was highly oxidized and functional groups such as $-\mathrm{COOH}$, $-\mathrm{OH}$ were successfully added on the GO planes [50-53]. The new peak around $1600 \mathrm{~cm}^{-1}$ (d) of the carbon double bond $\mathrm{C}=\mathrm{C}$ stretching was observed in the VBTAC modified GO, which provided the evidence for the successful combination of VBTA with GO [3].

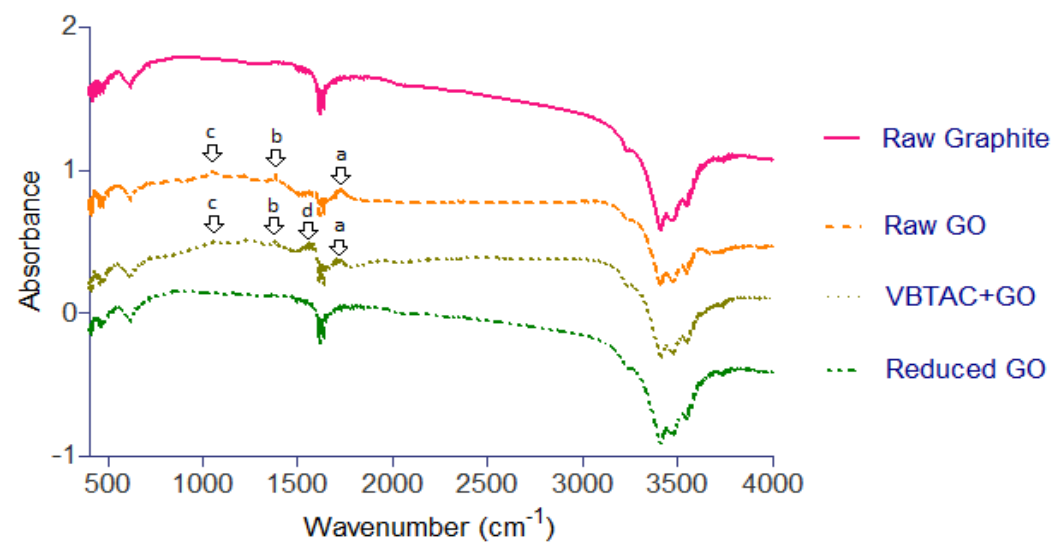

Figure 4. FTIR spectra of raw graphite, GO, reduced GO, and VBTAC-modified GO. 


\subsection{X-Ray Diffraction (XRD)}

XRD was used to determine the interlayer spacing (d) of the GO and its composite samples. The $d$-spacing was calculated according to the Bragg equation: $d=\lambda / 2 \sin \theta$. As shown in Figure 5, the spectra of raw graphite had a very strong characteristic peak at $2 \theta=26.5^{\circ}$ (interlayer spacing of $0.336 \mathrm{~nm}$, the (002) structure) $[54,55]$. The oxidation of graphite was expected to increase this interlayer distance (d-spacing). After oxidation, the diffraction curve of $\mathrm{GO}$ had a peak at $2 \theta=11^{\circ}$, which denoted an interlayer spacing of $0.803 \mathrm{~nm}$. The addition of oxygen-containing groups and water molecules into the interlayer spaces between graphene sheets resulted in the expansion of the interlayer spacing during the GO preparation process. It was also observed that a strong characteristic peak at $2 \theta=26.5^{\circ}$ entirely disappeared, which indicated the complete disruption of the original stacked (002) structure of raw graphite [55]. The results from both XRD and FTIR provided strong evidence for the formation of the intercalated GO with oxidized functional groups. The cationic ammonium groups of VBTAC were designed to further enter the interlayer space of $\mathrm{GO}$ and bond with the negative oxidized functional groups of the GO sheets. Figure 4 also showed that the VBTAC-modified GO had a shifted peak from $2 \theta=11^{\circ}$ to approximate $2 \theta=9^{\circ}$ (d-spacing of 0.981 ), indicating that the interspacing of GO was further improved by VBTAC.

After miniemulsion polymerization, the diffraction peaks of the XRD spectra of the nanocomposite samples were quite different from the GO samples. As shown in Figure 4 (below curves), the peaks at $9^{\circ}$ and $11^{\circ}$ corresponding to the GO and the VBTAC modified GO disappeared completely, indicating that the GO was completely exfoliated by the polymer chains. Similar phenomena were shown for nanoclay composites [3,56]. The pure polymer PMMA had a characteristic peak at $18.5^{\circ}$ [57], which became much less intensive and shifted to around $17.5^{\circ}$ in the formulations with $0.5 \%$ and $2 \%$ GO. This further provided the evidence for the successful exfoliation of GO in the polymer matrix, leading to the disappearance or change of the original PMMA structure.

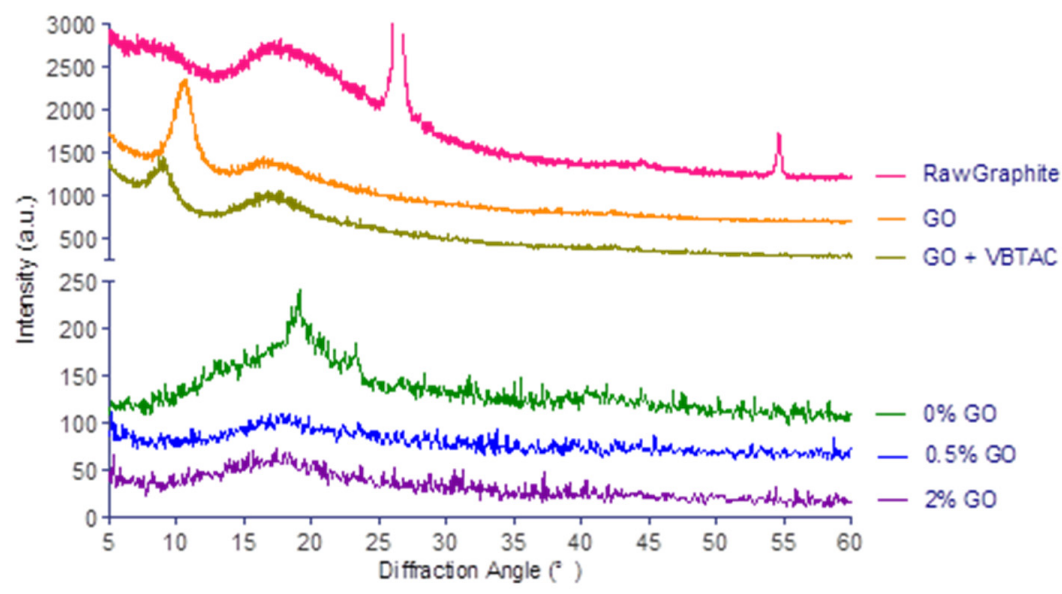

Figure 5. XRD spectra of raw graphite, GO, VBTAC-modified GO, GO/PMMA composites after miniemulsion with $0 \%, 0.5 \%$, and $2 \%$ GO.

\subsection{Thermal Stability Analysis}

The thermal stability of raw graphite, GO, and VBTAC modified GO was analyzed by TGA (Figure 6). Raw graphite did not exhibit any weight loss below $600{ }^{\circ} \mathrm{C}$, but about $8 \%$ of its weight was lost at $1000^{\circ} \mathrm{C}$. Regarding GO and VBTAC modified GO, approximate $10 \%$ weight loss was observed at $100{ }^{\circ} \mathrm{C}$, which was attributed to the evaporation of water molecules trapped between the GO sheets due to the existence of many oxygen-containing functional groups on the GO galleries. An addition of $30 \%$ weight loss occurred between 150 and $250^{\circ} \mathrm{C}$, caused by the removal of the labile oxygen-containing functional groups [58-60]. In the temperature range from 300 to $1000^{\circ} \mathrm{C}, \mathrm{GO}$ and VBTAC modified GO lost another $10 \%$ and $25 \%$ of their weight, respectively. The $10 \%$ weight loss of GO could be attributed 
to the combustion of the exfoliated carbon skeleton of GO [61]. Furthermore, VBTAC modified GO had $15 \%$ more weight loss in comparison with that of GO between 300 and $1000{ }^{\circ} \mathrm{C}$, which was attributed to the existence of the organic VBTAC. About $15 \mathrm{wt}$ \% of VBTAC was loaded with GO together and it entered the GO galleries and bonded with GO sheets.

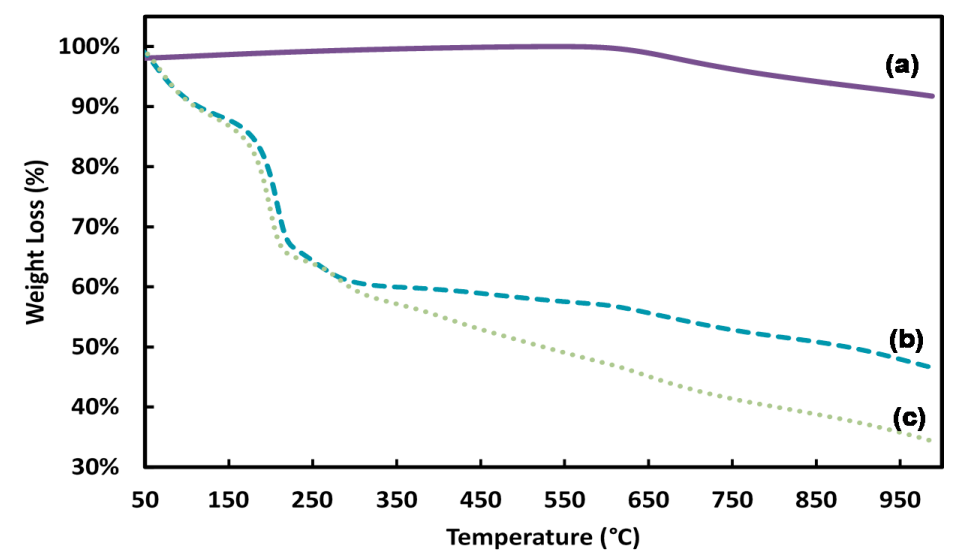

Figure 6. Thermogravimetric analysis (TGA) thermograms of (a) raw graphite, (b) GO, and (c) VBTAC treated GO.

\subsection{Particle Size Distribution of PMMA/GO Latex Droplets}

During the miniemulsion polymerization process, we found that a stable miniemulsion of GO was difficult to prepare even though we had already chosen the optimized modifier for an organophilic GO (VBTAC modified GO). Compared with nanoclay, GO had higher density and smaller size, which may be the reason for its instability in the monomer phase. To increase the viscosity of the organophilic phase but avoid the disturbance to the polymerization kinetics when using the surfactants with the longer carbon chain (OTAB, MTAB) or the complicated structure (QAL), we used PVA to further stabilize the organophilic phase. PVA is a water-soluble synthetic polymer and has been applied for stabilizing emulsions and miniemulsions in combination with other surfactants or by itself. Specifically, when PVA was applied with other surfactants, the resulted latex showed better emulsion fluidity and stability and exhibited improved performance characteristics, such as excellent tackiness for adhesives, and better freeze-thaw stability [62-65]. PVA was used in our latex formulation to increase the viscosity for two reasons. First, higher viscosity providing by the PVA means the reduction in the collision between particles caused by mechanical processing, so that the particle size can be more precisely controlled. It is known that semi-vigorous agitation must be employed to suspend and disperse all nano-sized droplets, and the agitation could cause droplets to collide, merge and lose the encapsulated core during the miniemulsion formation and polymerization processes. Second, higher viscosity can help to stabilize the latex after polymerization, which agrees well with the later latex stability study (Figure 9). Figure 7a showed that the average particle size decreased slightly with the increase of PVA content in the latex, which was similar to those obtained in previous studies [64-66]. Latex with 10\% and 20\% PVA had an average size of 250 and $230 \mathrm{~nm}$, respectively. For latex with $0 \%$ and 5\% PVA, a second peak representing the particles with the sizes of more than $4 \mu \mathrm{m}$ appeared, resulting from the particle aggregation induced by the collision.

The GO loading affected the particle sizes of latex droplets as well. All experiments were carried out in triplicate. An analysis of variance (ANOVA) with a Turkey test under a 95\% confidence interval $(\mathrm{a}=0.05)$ was used for statistical analysis. Figure $7 \mathrm{~b}$ illustrated that the GO loading significantly increased the average particle sizes of latex droplets. To be more specific, the average particle size of PMMA without GO was about $200 \mathrm{~nm}$. When the GO loading was increased to $0.25 \%$ and $0.5 \%$, the particle size slightly increased to around $290 \mathrm{~nm}$. This could be attributed to the encapsulation of GO particles inside the polymer droplets. In these cases, the thickness of the GO core was about $90 \mathrm{~nm}$. 


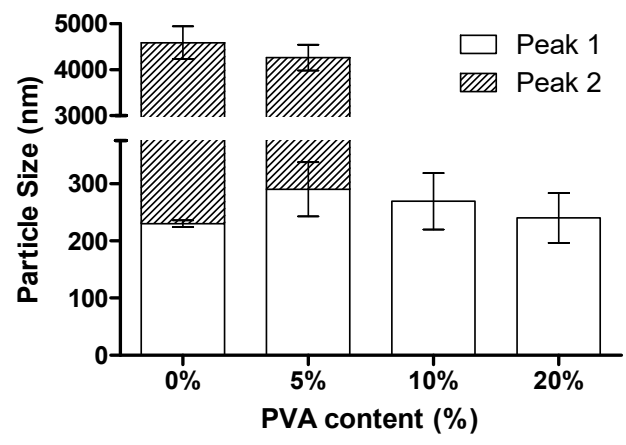

(a)

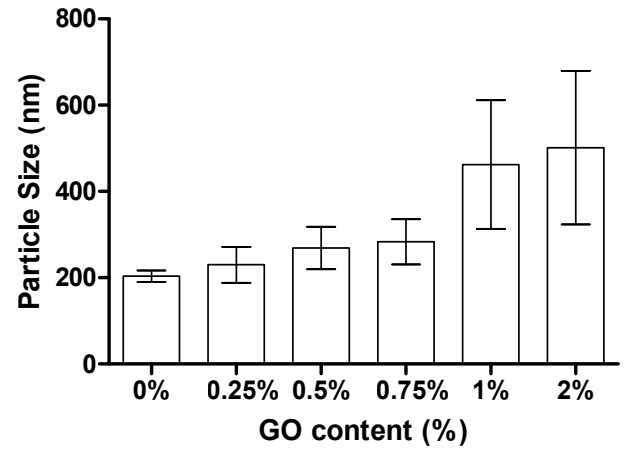

(b)

Figure 7. Effect of (a) the PVA loading (0.5\% of GO), and (b) the GO loading (10\% PVA) on the particle sizes and size distribution of nanocomposite PMMA/GO latex prepared via miniemulsion polymerization.

When the GO loading increased to $0.75 \%$ and $1 \%$, the average particle size increased to about 400 and $480 \mathrm{~nm}$, implying that GO aggregation occurred and some excessive GO could not be encapsulated by the polymer droplets. When the GO loading was increased to $2 \%$, the particle size increased to about $520 \mathrm{~nm}$ and further suggested the aggregation formation of the excess GO particles. The particle size at the GO loading of $0.25 \%$ and $0.5 \%$ were very close; however, the particle size increased significantly when GO loading reached $0.75 \%$ and the excess and unencapsulated GO might exist in the system. In a higher GO loading $(>0.5 \%)$, the formation of larger particle sizes and higher size dispersity may be explained as follows. Firstly, the encapsulation of more GO particles produced the larger composite droplets. Secondly, the "empty" polymer droplets were much smaller than droplets with GO inside, resulting in a large size dispersity. Thirdly, the GO sheets that were not encapsulated was easy to aggregate together and formed large clusters. Thus, a GO loading of $0.5 \%$ was chosen for further miniemulsion stability and morphology study.

\subsection{Morphologies of GO, PMMA/GO Latex and Its Melt Films}

Both SEM and TEM were used to measure the morphologies of the modified GO, PMMA/GO latex, and its melting films with or without the GO exfoliation. Figure 8a showed the structures of GO after VBTAC modification. The GO sheets with excellent transparency were overlapping together. This agreed well with the aforementioned XRD results, demonstrating that the increase of $d$-spacing between the GO galleries after oxidation and VBTAC intercalation. The average diameter of the GO sheet was about 200-500 nm and the thicknesses were in the order of several nanometers. As shown in Figure 8b,c, the pure PMMA latex droplets were synthesized based on the basic recipe in Table 2, consisting of spherical particles with an average size of $200 \mathrm{~nm}$ and uniform size distribution.

Figure $8 \mathrm{~d}$,e illustrate the morphologies of nanocomposite latex in the presence of $0.5 \%$ VBTAC treated GO using the miniemulsion polymerization and the encapsulation method. It was observed that the average particle size of PMMA/GO nanocomposite was approximately $250 \mathrm{~nm}$. Some large particles with the particle size larger than $300 \mathrm{~nm}$ existed in the system as well. In the TEM image (Figure 8e), these large particles had dark cores representing the modified GO nanosheets inside the PMMA shell. Besides, the absence of un-encapsulated GO sheets, suggested that GO nanosheets were completely encapsulated by the PMMA shells. Figure $8 \mathrm{f}$ showed the melted film of this PMMA/GO nanocomposite film. GO nanoplatelets with several-nanometer thicknesses were seen in the polymer matrix, indicating the exfoliation and encapsulation of GO nanosheets after polymerization [66]. The VBTAC modification increased the interlayer spacing of GO and facilitated the intercalation of the monomer into the GO galleries. After that, the reaction of double bonds of the VBTAC located on the 
GO sheet and the monomer MMA during the polymerization process further facilitated the exfoliation of the polymer chain into the GO galleries.

To further confirm the effect of GO modified by the reactive modifier VBTAC, we conducted the same experiment using the GO without any modification. The morphologies of nanocomposite latex and its melting film prepared from the untreated GO $(0.5 \%)$ were shown in Figure $8 \mathrm{~g}-\mathrm{i}$. Both SEM and TEM images (Figure 8g,h) clearly illustrated that the polymer/GO droplets formed the aggregates and only a few spherical particles were observed. Some flake shape particles with the size around $1 \mu \mathrm{m}$ existed, which could be the un-exfoliated or aggregated GO sheets. In Figure 8h, some aggregates of polymer droplets and dark "grainy" shaped GO clusters with a size of about $1 \mu \mathrm{m}$ were clearly shown in the TEM image. This result indicated that without the VBTAC treatment, the monomer was not able to cover or enter the galleries of the hydrophilic GO, which restrained both exfoliation and encapsulation of GO by the polymer particles during miniemulsion polymerization. Hydrophilic GO stayed in the water phase during the entire polymerization process. The image of the latex nanocomposite melting film (Figure 8i) revealed that the majority of GO sheets were not exfoliated and formed aggregated clusters dispersing in the polymer matrix. In summary, the VBTAC modification was critical to forming stable latex of the exfoliated and encapsulated PMMA/GO nanocomposite. The particle sizes of the nanocomposite droplets from these images agreed well with that from the DLS analysis.

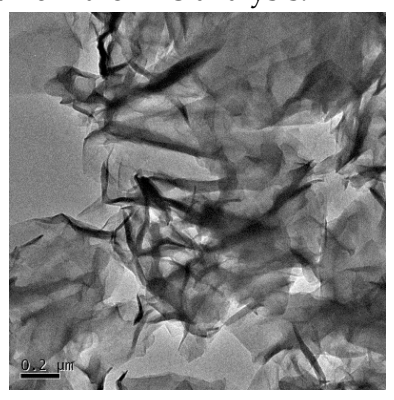

(a)

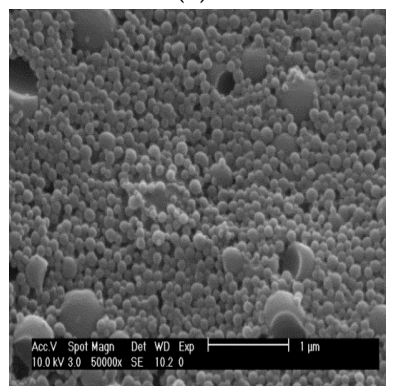

(d)

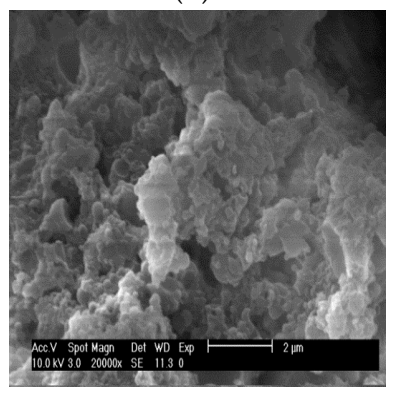

(g)

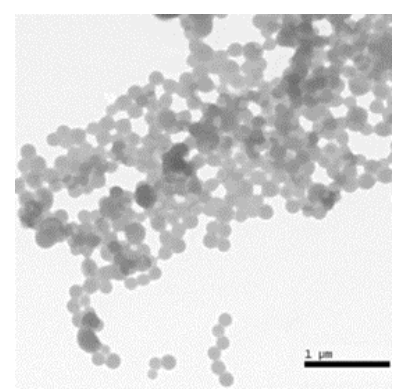

(b)

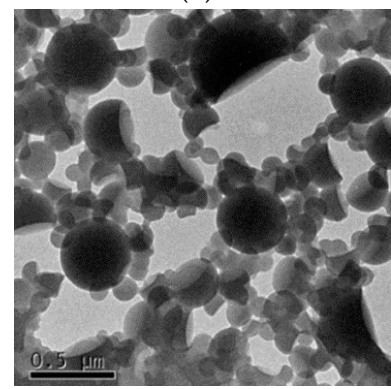

(e)

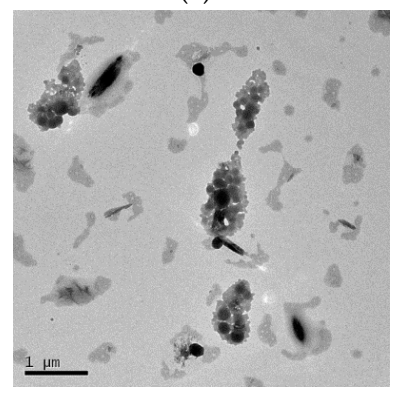

(h)

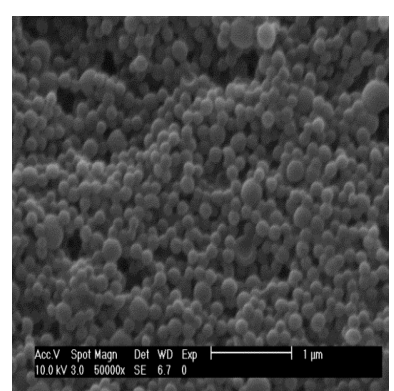

(c)

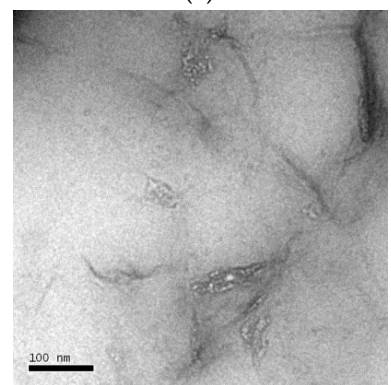

(f)

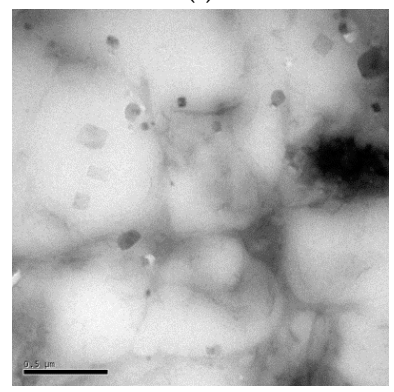

(i)

Figure 8. Images of (a) TEM of VBTAC modified GO after sonication; (b) TEM and (c) SEM of neat PMMA nano-droplets; (d) SEM and (e) TEM of miniemulsions; (f) TEM of the melted film of nanocomposites of the VBTAC modified GO (0.5\%) encapsulated by PMMA; (g) SEM and (h) TEM of miniemulsions and (i) TEM of the melted film of nanocomposites of untreated GO (0.5\%) with PMMA. 


\subsection{Molecular Weight}

The molecular weight (Mw, Mn) and the polydispersity index (PDI) of PMMA/GO nanocomposites with different VBTAC-modified GO loading levels were shown in Table 2. The molecular weight of the pure PMMA was about 130,000, which was comparable with the commercial- grade PMMA (150,000, Sigma Aldrich). It denotes that miniemulsion polymerization is a viable method to synthesize high molecular weight polymers. The Mw of PMMA decreased with the addition of the modified GO. The existence of GO nanoparticles in the miniemulsion obstructed the growth of the polymer chain. Similar findings were observed in the miniemulsions of polymer encapsulated nanoclay composites $[47,67]$. This was attributed to the irreversible reaction between the surface functional groups of the nanoclay and the growing radicals, where this reaction reduced radical concentration and, therefore, directly affected the polymerization kinetics $[47,67]$. However, in this study, it was observed that with the increase of the modified GO loading from $1 \%$ to $2 \%$, both Mw and PDI of nanocomposites were slightly higher than that of $0.5 \%$ of the modified GO. Our particle size analysis also provided some evidence that higher loading of GO might lead to some excess GO without encapsulation. The excess GO acted as the stabilizer for the miniemulsion and facilitated the polymerization reaction. The PDI increased with the GO loading, which agreed well with the polymer encapsulated nanoclay nanocomposite study. Nanoclay or nanodimensional GO in the miniemulsion disturbed the polymerization equilibrium and led to more chain transfer chances and the termination of propagation radicals $[68,69]$.

Table 2. The molecular weight of polymerized latex of PMMA with different GO loading levels.

\begin{tabular}{cccc}
\hline GO Loading $\%$ & Mw & Mn & PDI \\
\hline $0 \%$ GO & $1.28 \mathrm{E}+06$ & $4.14 \mathrm{E}+05$ & 3.11 \\
$0.5 \% \mathrm{GO}$ & $2.15 \mathrm{E}+05$ & $4.49 \mathrm{E}+04$ & 4.80 \\
$1 \% \mathrm{GO}$ & $2.99 \mathrm{E}+05$ & $6.55 \mathrm{E}+04$ & 4.57 \\
$2 \% \mathrm{GO}$ & $3.93 \mathrm{E}+05$ & $6.14 \mathrm{E}+04$ & 6.40 \\
\hline
\end{tabular}

\subsection{Stability of Latex}

Figure 9 shows that the stability of latex varied at different GO loading and the PVA percentage. Latex with $0.5 \%$ VBTAC modified GO and $10 \%$ and $20 \%$ PVA (Figure $9 \mathrm{a}, \mathrm{f}$ ) showed good stability over three months, and no visible separation or sedimentation was observed. However, the latex without any GO had a slightly separated phase (Figure 9g) in the addition of $10 \%$ PVA. It indicated that in a pure PMMA miniemulsion, the addition of PVA reduced miniemulsion stability. It could be attributed to the water solubility of PVA, which preferred to stay in the water phase and impeded the formation of stable miniemulsion. When $0.5 \%$ organophilic GO was used as the core material, both the particle sizes and PDI of nanocomposite miniemulsion increased with the encapsulation of the GO, in comparison with the pure PMMA miniemulsion (Table 2). The particles with a higher PDI indicated that they were not stable and easier to aggregate to form larger particles. The particle aggregation is a result of the collisions caused by the Brownian motion of particles under the mechanical agitation. In this case, the addition of PVA could increase the viscosity and reduce the particle collisions to form aggregates. Figure $9 \mathrm{~d}-\mathrm{f}$ showed the effect of PVA percentage on latex stability when the GO loading was kept at $0.5 \%$. The increase in viscosity caused by the addition of PVA (from $5 \%$ to $20 \%$ ) reduced the collision between composite particles, which was induced by mechanical processing. Mechanical agitation caused droplets to collide, merge, and lose the encapsulated core. The large black particles were shown in Figure 9d,e, indicating that the aggregation of the polymer/GO droplets was formed due to the mechanical collision when the PVA percentage was too low. Further, when the GO loading increased from $0.5 \%$ to $1 \%$ and $2 \%$ (Figure $9 a-c$ ), the polymer droplets seemed to be easily separated from the aqueous phase and settled on the bottom. This might be caused by the existence of the excess organophilic and non-encapsulated GO particles, that disturbed the latex equilibrium and formed 
aggregates during the polymerization process. Due to the high degree of exfoliation of GO, only a low amount of GO $(0.5 \%)$ was required for the encapsulation purpose.

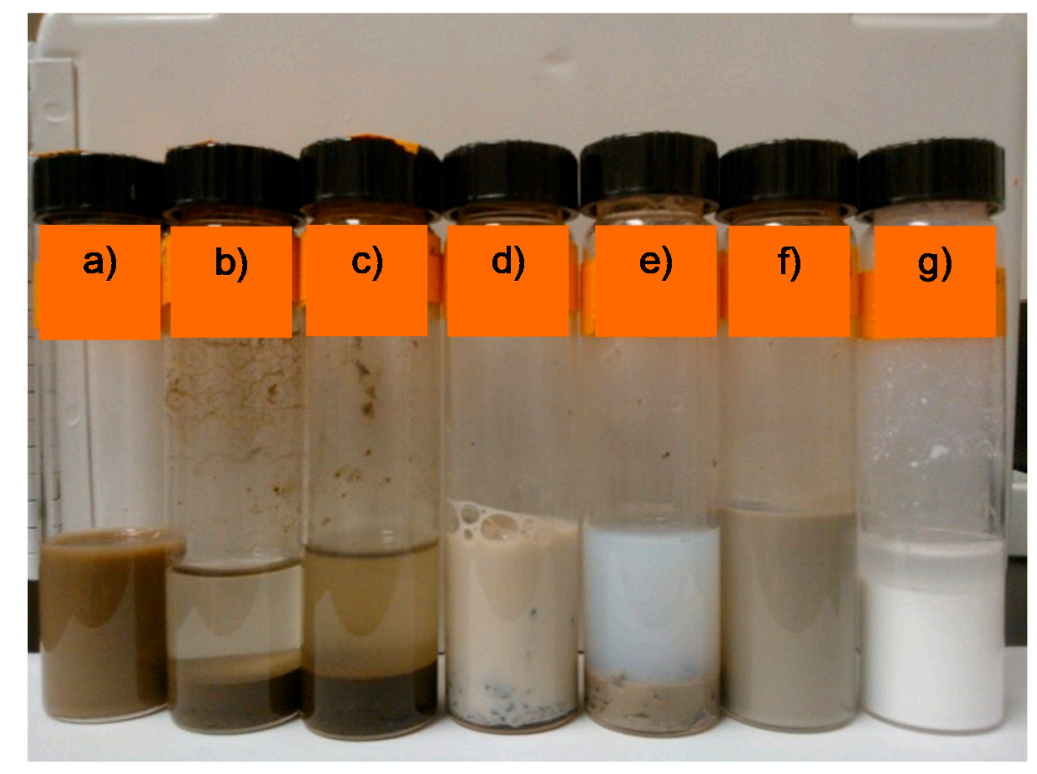

Figure 9. Stability of miniemulsion latex after sitting for more than 3 months. (a) $0.5 \%$ GO, 10\% PVA, (b) $1 \%$ GO, 10\% PVA, (c) 2\% GO, 10\% PVA, (d) $0.5 \%$ GO, $0 \%$ PVA, (e) $0.5 \%$ GO, 5\% PVA, (f) $0.5 \%$ GO, 20\% PVA, (g) $0 \%$ GO, 10\% PVA.

\section{Discussion \& Conclusions}

The incompatibility between graphene oxide and the hydrophobic organic polymer impedes the development of the GO-based nanocomposites for their broad applications as energy, reinforced, and environmental materials. The dispersion of nano-dimensional GO plays a critical role in the final material properties such as percolation threshold, electric conductivity, and mechanical properties. In this study, different types of modifiers, including anionic surfactant without the reactive group (SDBS), with the reactive group (AMPS), cationic quaternary ammonium modifiers with the reactive end group, and various carbon chains lengths or backbone structures (OTAB, MTAB, QAL, VBTAC), were used to optimize the organophilic GO to determine which was the best for the stability and reactivity within its monomeric medium. The anionic surfactant either SDBS or AMPS has a negative end group (sulfonic acid) in one end and a hydrophobic group in another end. Some literature reported that anionic surfactant could stabilize in the GO [48,49]. In this case, the negative charge of the surfactant could repel the negative charge in the interlayer of GO, which allows GO to only contact on the hydrophobic end of the surfactant. Thus, these two anionic surfactants result in a relatively stable GO in the water phase but not in the organophilic phase, which agrees well with our experimental observation. It is not suitable for our proposed purpose. Further, different cationic quaternary ammonium modifiers were used to modify GO. It is proposed that the cationic ends of the modifiers bind with anionic functional groups of GO interlayers together to allow the charge neutralization. Because the hydrophobic ends exist in both the modifiers and the GO after their charge neutralization, the nanohybrids change from hydrophilic to organophilic. Our results further approved this mechanism. It was shown that all the nanohybrids modified by cationic quaternary ammonium modifiers (VBTAC, OTAB, CTAB) were precipitated out from the water phase (Figure 2). However, in surprise, the QAL modified GO stayed in the water phase. Since QAL has the smallest percentage of cationic charges (only on their phenolic hydroxyl groups) and the most space hindrance, GO might not be easy to reach the cationic charge groups to form an organophilic nanohybrid. Both OTAB and $\mathrm{CTAB}$ do not own the reactive end group (carbon double bond) for further reactions with the monomer. Meanwhile, the long carbon chain significantly increases the viscosity of the monomer phase with GO 
inside, which impedes the further miniemulsion reaction kinetics. Therefore, among these modifiers, VBTAC met all of our required properties.

The VBTAC not only converted GO from hydrophilic to organophilic but also allowed the reactive end groups to further bind with the polymer together during the subsequent free radical miniemulsion polymerization process. A stable latex of the exfoliated PMMA encapsulated nano-dimensional GO composite was successfully synthesized using the VBTAC-modified GO with the addition of PVA. The addition of a $10 \%$ PVA polymer played an important role in the latex stability by increasing viscosity to impede the mechanical collisions between the monomer and polymer-encapsulated GO nanoparticles. The XRD and TEM and SEM images showed the exfoliation of polymer/GO nanocomposites. The uniform distribution of the exfoliated and nano-dimensional GO in the polymer matrix formed a stable latex with an average particle size of less than $300 \mathrm{~nm}$ with the ability to remain in solution for long-term storage. The next step following this study is to determine a variety of other properties needed from this uniform distribution of exfoliated GO in the polymer nanocomposite for various applications.

Author Contributions: Conceptualization, Z.T., L.W., H.W.; methodology, H.W., and L.W.; validation, Z.T., L.W., H.W., and M.C.; formal analysis, Z.T., L.W., H.W.; investigation, L.W., H.W.; data curation, L.W., H.W.; writing—original draft preparation, L.W., and H.W.; writing—review and editing, Z.T., H.W., S.M., H.L., M.C.; visualization, L.W. and H.W.; supervision, Z.T.; project administration, Z.T.; funding acquisition, L.W., and Z.T. All authors have read and agreed to the published version of the manuscript.

Funding: This research received no external funding.

Acknowledgments: The authors thank the major research service center (RSC) staff at the University of Florida for the assistance of SEM, TEM, and XRD studies. The author also thanks the Chinese Scholarship Council (CSC) to provide financial support for F.W. to visit the USA. Partial funding was also provided for F.W. by the Hunan Provincial Key R\&D Program of China (2017WK2022).

Conflicts of Interest: The authors declare no conflict of interest.

\section{References}

1. Moniruzzaman, M.; Winey, K.I. Polymer nanocomposites containing carbon nanotubes. Macromolecules 2006, 39, 5194-5205. [CrossRef]

2. Huang, J.C. Carbon black filled conducting polymers and polymer blends. Adv. Polym. Technol. J. Polym. Process. Inst. 2002, 21, 299-313.

3. Tong, Z.; Deng, Y. Synthesis of polystyrene encapsulated nanosaponite composite latex via miniemulsion polymerization. Polymer 2007, 48, 4337-4343. [CrossRef]

4. Jairam, S.; Tong, Z.; Wang, L.; Welt, B. Encapsulation of a biobased lignin-saponite nanohybrid into polystyrene co-butyl acrylate (PSBA) latex via miniemulsion polymerization. ACS Sustain. Chem. Eng. 2013, 1, 1630-1637. [CrossRef]

5. Choi, S.; Han, S.I.; Kim, D.; Hyeon, T.; Kim, D.-H. High-performance stretchable conductive nanocomposites: Materials, processes, and device applications. Chem. Soc. Rev. 2019, 48, 1566-1595. [CrossRef]

6. Liu, J.; Ma, Q.; Huang, Z.; Liu, G.; Zhang, H. Recent progress in graphene-based noble-metal nanocomposites for electrocatalytic applications. Adv. Mater. 2019, 31, 1800696. [CrossRef]

7. Farahani, R.D.; Dubé, M.; Therriault, D. Three-dimensional printing of multifunctional nanocomposites: Manufacturing techniques and applications. Adv. Mater. 2016, 28, 5794-5821. [CrossRef]

8. Bhattacharya, S.; Samanta, S.K. Soft-nanocomposites of nanoparticles and nanocarbons with supramolecular and polymer gels and their applications. Chem. Rev. 2016, 116, 11967-12028. [CrossRef]

9. Boland, C.S.; Khan, U.; Ryan, G.; Barwich, S.; Charifou, R.; Harvey, A.; Backes, C.; Li, Z.; Ferreira, M.S.; Möbius, M.E. Sensitive electromechanical sensors using viscoelastic graphene-polymer nanocomposites. Science 2016, 354, 1257-1260. [CrossRef]

10. Lee, C.; Wei, X.; Kysar, J.W.; Hone, J. Measurement of the elastic properties and intrinsic strength of monolayer graphene. Science 2008, 321, 385-388.

11. Balandin, A.A.; Ghosh, S.; Bao, W.; Calizo, I.; Teweldebrhan, D.; Miao, F.; Lau, C.N. Superior thermal conductivity of single-layer graphene. Nano Lett. 2008, 8, 902-907. [CrossRef] [PubMed] 
12. Du, X.; Skachko, I.; Barker, A.; Andrei, E.Y. Approaching ballistic transport in suspended graphene. Nat. Nanotechnol. 2008, 3, 491-495. [PubMed]

13. Bunch, J.S.; Verbridge, S.S.; Alden, J.S.; Van Der Zande, A.M.; Parpia, J.M.; Craighead, H.G.; McEuen, P.L. Impermeable atomic membranes from graphene sheets. Nano Lett. 2008, 8, 2458-2462. [CrossRef] [PubMed]

14. Chang, H.; Wu, H. Graphene-based nanocomposites: Preparation, functionalization, and energy and environmental applications. Energy Environ. Sci. 2013, 6, 3483-3507. [CrossRef]

15. Pei, S.; Wei, Q.; Huang, K.; Cheng, H.-M.; Ren, W. Green synthesis of graphene oxide by seconds timescale water electrolytic oxidation. Nat. Commun. 2018, 9, 1-9. [CrossRef]

16. Chen, J.; Zhang, Y.; Zhang, M.; Yao, B.; Li, Y.; Huang, L.; Li, C.; Shi, G. Water-enhanced oxidation of graphite to graphene oxide with controlled species of oxygenated groups. Chem. Sci. 2016, 7, 1874-1881. [CrossRef] [PubMed]

17. Shen, J.; Hu, Y.; Shi, M.; Lu, X.; Qin, C.; Li, C.; Ye, M. Fast and facile preparation of graphene oxide and reduced graphene oxide nanoplatelets. Chem. Mater. 2009, 21, 3514-3520. [CrossRef]

18. Kim, H.; Abdala, A.A.; Macosko, C.W. Graphene/polymer nanocomposites. Macromolecules 2010, 43, 6515-6530. [CrossRef]

19. Etmimi, H.M.; Sanderson, R.D. New approach to the synthesis of exfoliated polymer/graphite nanocomposites by miniemulsion polymerization using functionalized graphene. Macromolecules 2011, 44, 8504-8515. [CrossRef]

20. Putz, K.W.; Compton, O.C.; Palmeri, M.J.; Nguyen, S.T.; Brinson, L.C. High-nanofiller-content graphene oxide-polymer nanocomposites via vacuum-assisted self-assembly. Adv. Funct. Mater. 2010, 20, 3322-3329. [CrossRef]

21. Xing, J.; Deng, B.; Liu, Q. Effect of graphene nanoplatelets on the performance of polyphenylene sulfide composites produced by melt intercalation. High Perform. Polym. 2018, 30, 519-526. [CrossRef]

22. Bijarimi, M.; Amirul, M.; Norazmi, M.; Ramli, A.; Desa, M.S.Z.; Desa, M.D.A.; Samah, M.A.A. Preparation and characterization of poly (lactic acid)(PLA)/polyamide 6 (PA6)/graphene nanoplatelet (GNP) blends bio-based nanocomposites. Mater. Res. Express 2019, 6, 055044. [CrossRef]

23. Mishra, S.K.; Tripathi, S.N.; Choudhary, V.; Gupta, B.D. Surface plasmon resonance-based fiber optic methane gas sensor utilizing graphene-carbon nanotubes-poly (methyl methacrylate) hybrid nanocomposite. Plasmonics 2015, 10, 1147-1157. [CrossRef]

24. Rajabi, M.; Mahanpoor, K.; Moradi, O. Preparation of PMMA/GO and PMMA/GO-Fe3O4 nanocomposites for malachite green dye adsorption: Kinetic and thermodynamic studies. Compos. Part B Eng. 2019, 167, 544-555. [CrossRef]

25. Thomassin, J.-M.; Trifkovic, M.; Alkarmo, W.; Detrembleur, C.; Jérôme, C.; Macosko, C. Poly (methyl methacrylate)/graphene oxide nanocomposites by a precipitation polymerization process and their dielectric and rheological characterization. Macromolecules 2014, 47, 2149-2155. [CrossRef]

26. Wang, W.-P.; Pan, C.-Y. Preparation and characterization of polystyrene/graphite composite prepared by cationic grafting polymerization. Polymer 2004, 45, 3987-3995. [CrossRef]

27. Hu, H.; Wang, X.; Wang, J.; Wan, L.; Liu, F.; Zheng, H.; Chen, R.; Xu, C. Preparation and properties of graphene nanosheets-polystyrene nanocomposites via in situ emulsion polymerization. Chem. Phys. Lett. 2010, 484, 247-253. [CrossRef]

28. Poddar, M.K.; Pradhan, S.; Moholkar, V.S.; Arjmand, M.; Sundararaj, U. Ultrasound-assisted synthesis and characterization of polymethyl methacrylate/reduced graphene oxide nanocomposites. AIChE J. 2018, 64, 673-687. [CrossRef]

29. Fadil, Y.; Agarwal, V.; Jasinski, F.; Thickett, S.C.; Minami, H.; Zetterlund, P.B. Electrically conductive polymer/rGO nanocomposite films at ambient temperature via miniemulsion polymerization using GO as surfactant. Nanoscale 2019, 11, 6566-6570. [CrossRef]

30. Zhang, L.; Yang, W.; Jiang, Z.; He, F.; Zhang, K.; Fan, J.; Wu, J. Graphene oxide-modified microencapsulated phase change materials with high encapsulation capacity and enhanced leakage-prevention performance. Appl. Energy 2017, 197, 354-363. [CrossRef]

31. Thickett, S.C.; Wood, N.; Ng, Y.H.; Zetterlund, P.B. Hollow hybrid polymer-graphene oxide nanoparticles via Pickering miniemulsion polymerization. Nanoscale 2014, 6, 8590-8594. [CrossRef] [PubMed] 
32. Huynh, V.T.; Nguyen, D.; Such, C.H.; Hawkett, B.S. Polymer coating of graphene oxide via reversible addition-fragmentation chain transfer mediated emulsion polymerization. J. Polym. Sci. Part A Polym. Chem. 2015, 53, 1413-1421. [CrossRef]

33. Pham, V.H.; Dang, T.T.; Hur, S.H.; Kim, E.J.; Chung, J.S. Highly conductive poly (methyl methacrylate)(PMMA)—Reduced graphene oxide composite prepared by self-assembly of PMMA latex and graphene oxide through electrostatic interaction. ACS Appl. Mater. Interfaces 2012, 4, 2630-2636. [CrossRef] [PubMed]

34. Pan, G.; Sudol, E.D.; Dimonie, V.L.; El-Aasser, M.S. Nitroxide-mediated living free radical miniemulsion polymerization of styrene. Macromolecules 2001, 34, 481-488. [CrossRef]

35. Taden, A.; Landfester, K. Crystallization of poly (ethylene oxide) confined in miniemulsion droplets. Macromolecules 2003, 36, 4037-4041. [CrossRef]

36. Schork, F.J.; Luo, Y.; Smulders, W.; Russum, J.P.; Butté, A.; Fontenot, K. Miniemulsion polymerization. Adv. Polym. Sci. 2005, 175, 129-255.

37. Asua, J.M. Miniemulsion polymerization. Prog. Polym. Sci. 2002, 27, 1283-1346. [CrossRef]

38. Che Man, S.; Thickett, S.C.; Whittaker, M.R.; Zetterlund, P.B. Synthesis of polystyrene nanoparticles "armoured" with nanodimensional graphene oxide sheets by miniemulsion polymerization. J. Polym. Sci. Part A Polym. Chem. 2013, 51, 47-58. [CrossRef]

39. Che Man, S.; Mohd Yusof, N.; Whittaker, M.R.; Thickett, S.C.; Zetterlund, P.B. Influence of monomer type on miniemulsion polymerization systems stabilized by graphene oxide as sole surfactant. J. Polym. Sci. Part A Polym. Chem. 2013, 51, 5153-5162. [CrossRef]

40. Teo, G.H.; Ng, Y.H.; Zetterlund, P.B.; Thickett, S.C. Factors influencing the preparation of hollow polymer-graphene oxide microcapsules via Pickering miniemulsion polymerization. Polymer 2015, 63, 1-9. [CrossRef]

41. Tokuda, M.; Yamane, M.; Thickett, S.C.; Minami, H.; Zetterlund, P.B. Synthesis of polymeric nanoparticles containing reduced graphene oxide nanosheets stabilized by poly (ionic liquid) using miniemulsion polymerization. Soft Matter 2016, 12, 3955-3962. [CrossRef] [PubMed]

42. Tan, Y.; Fang, L.; Xiao, J.; Song, Y.; Zheng, Q. Grafting of copolymers onto graphene by miniemulsion polymerization for conductive polymer composites: Improved electrical conductivity and compatibility induced by interfacial distribution of graphene. Polym. Chem. 2013, 4, 2939-2944. [CrossRef]

43. Fadil, Y.; Jasinski, F.; Guok, T.W.; Thickett, S.C.; Minami, H.; Zetterlund, P.B. Pickering miniemulsion polymerization using graphene oxide: Effect of addition of a conventional surfactant. Polym. Chem. 2018, 9 , 3368-3378. [CrossRef]

44. Man, S.C.; Ly, D.; Whittaker, M.R.; Thickett, S.C.; Zetterlund, P.B. Nano-sized graphene oxide as sole surfactant in miniemulsion polymerization for nanocomposite synthesis: Effect of $\mathrm{pH}$ and ionic strength. Polymer 2014, 55, 3490-3497. [CrossRef]

45. Hummers, W.S., Jr.; Offeman, R.E. Preparation of graphitic oxide. J. Am. Chem. Soc. 1958, 80, 1339. [CrossRef]

46. Ten, E.; Vermerris, W. Recent developments in polymers derived from industrial lignin. J. Appl. Polym. Sci. 2015, 132, 42069. [CrossRef]

47. Zhong, Y.; Zhu, Z.; Wang, S.-Q. Synthesis and rheological properties of polystyrene/layered silicate nanocomposite. Polymer 2005, 46, 3006-3013. [CrossRef]

48. Deraguin, B.V.; Landau, L. Theory of the stability of strongly charged lyophobic sols and of the adhesion of strongly charged particles in solution of electrolytes. Acta Physicochim USSR 1941, 14, 633-662.

49. Verwey, E.J.W. Theory of the stability of lyophobic colloids. J. Phys. Chem. 1947, 51, 631-636. [CrossRef]

50. Liu, H.; Zhang, L.; Guo, Y.; Cheng, C.; Yang, L.; Jiang, L.; Yu, G.; Hu, W.; Liu, Y.; Zhu, D. Reduction of graphene oxide to highly conductive graphene by Lawesson's reagent and its electrical applications. J. Mater. Chem. C 2013, 1, 3104-3109. [CrossRef]

51. Zangmeister, C.D. Preparation and evaluation of graphite oxide reduced at 220 C. Chem. Mater. 2010, 22, 5625-5629. [CrossRef]

52. Nethravathi, C.; Rajamathi, M. Chemically modified graphene sheets produced by the solvothermal reduction of colloidal dispersions of graphite oxide. Carbon 2008, 46, 1994-1998. [CrossRef]

53. Titelman, G.I.; Gelman, V.; Bron, S.; Khalfin, R.L.; Cohen, Y.; Bianco-Peled, H. Characteristics and microstructure of aqueous colloidal dispersions of graphite oxide. Carbon 2005, 43, 641-649. [CrossRef] 
54. Uhl, F.M.; Yao, Q.; Nakajima, H.; Manias, E.; Wilkie, C.A. Expandable graphite/polyamide-6 nanocomposites. Polym. Degrad. Stab. 2005, 89, 70-84. [CrossRef]

55. Park, S.; An, J.; Potts, J.R.; Velamakanni, A.; Murali, S.; Ruoff, R.S. Hydrazine-reduction of graphite-and graphene oxide. Carbon 2011, 49, 3019-3023. [CrossRef]

56. Khezri, K.; Haddadi-Asl, V.; Roghani-Mamaqani, H.; Salami-Kalajahi, M. Encapsulation of organomodified montmorillonite with PMMA via in situ SR\&NI ATRP in miniemulsion. J. Polym. Res. 2012, 19, 9868.

57. Lan, F.; Liu, K.-X.; Jiang, W.; Zeng, X.-B.; Wu, Y.; Gu, Z.-W. Facile synthesis of monodisperse superparamagnetic Fe3O4/PMMA composite nanospheres with high magnetization. Nanotechnology 2011, 22, 225604. [CrossRef]

58. Li, C.; Wang, X.; Liu, Y.; Wang, W.; Wynn, J.; Gao, J. Using glucosamine as a reductant to prepare reduced graphene oxide and its nanocomposites with metal nanoparticles. J. Nanopart. Res. 2012, 14, 875. [CrossRef]

59. Wu, T.; Wang, X.; Qiu, H.; Gao, J.; Wang, W.; Liu, Y. Graphene oxide reduced and modified by soft nanoparticles and its catalysis of the Knoevenagel condensation. J. Mater. Chem. 2012, 22, 4772-4779. [CrossRef]

60. Wang, X.; Wen, X.; Liu, Z.; Tan, Y.; Yuan, Y.; Zhang, P. Rapid and efficient synthesis of soluble graphene nanosheets using N-methyl-p-aminophenol sulfate as a reducing agent. Nanotechnology 2012, 23, 485604. [CrossRef]

61. Wang, P.; Tang, Y.; Dong, Z.; Chen, Z.; Lim, T.-T. Ag-AgBr/TiO 2/RGO nanocomposite for visible-light photocatalytic degradation of penicillin G. J. Mater. Chem. A 2013, 1, 4718-4727. [CrossRef]

62. Kim, N.; Sudol, E.D.; Dimonie, V.L.; El-Aasser, M.S. Poly (vinyl alcohol) stabilization of acrylic emulsion polymers using the miniemulsion approach. Macromolecules 2003, 36, 5573-5579. [CrossRef]

63. Kim, N.; Sudol, E.D.; Dimonie, V.L.; El-Aasser, M.S. Comparison of conventional and miniemulsion copolymerizations of acrylic monomers using poly (vinyl alcohol) as the sole stabilizer. Macromolecules 2004, 37, 2427-2433. [CrossRef]

64. Yuki, K.; Nakamae, M.; Sato, T.; Maruyama, H.; Okaya, T. Physical properties of acrylic copolymer emulsions using poly (vinyl alcohol) as a protective colloid in comparison with those using surfactants. Polym. Int. 2000, 49, 1629-1635. [CrossRef]

65. Robeson, L.M.; Vratsanos, M.S. Mechanical characterization of vinyl acetate based emulsion polymer blends. In Macromolecular Symposia; WILEY-VCH Verlag: Weinheim, Germany, 2000; Volume 1, pp. 117-138.

66. Choi, K.S.; Liu, F.; Choi, J.S.; Seo, T.S. Fabrication of free-standing multilayered graphene and poly (3, 4-ethylenedioxythiophene) composite films with enhanced conductive and mechanical properties. Langmuir 2010, 26, 12902-12908. [CrossRef] [PubMed]

67. Samakande, A.; Sanderson, R.D.; Hartmann, P.C. Encapsulated clay particles in polystyrene by RAFT mediated miniemulsion polymerization. J. Polym. Sci. Part A Polym. Chem. 2008, 46, 7114-7126. [CrossRef]

68. Tong, Z.; Deng, Y. Kinetics of miniemulsion polymerization of styrene in the presence of organoclays. Macromol. Mater. Eng. 2008, 293, 529-537. [CrossRef]

69. Roghani-Mamaqani, H.; Haddadi-Asl, V.; Najafi, M.; Salami-Kalajahi, M. Preparation of tailor-made polystyrene nanocomposite with mixed clay-anchored and free chains via atom transfer radical polymerization. AIChE J. 2011, 57, 1873-1881. [CrossRef]

(C) 2020 by the authors. Licensee MDPI, Basel, Switzerland. This article is an open access article distributed under the terms and conditions of the Creative Commons Attribution (CC BY) license (http://creativecommons.org/licenses/by/4.0/). 